\title{
Laminin Molecular Domains which Alter Metastasis in a Murine Model
}

\author{
Sanford H. Barsky, C. N. Rao, Jeannette E. Williams, \\ and Lance A. Liotta \\ Laboratory of Pathology, National Cancer Institute, National \\ Institutes of Health, Bethesda, Maryland 20205
}

bstract. Human and murine tumor cells contain cell surface receptors for the basement membrane glycoprotein laminin. Since a biologic role for the receptor had not previously been demonstrated, we explored the possibility that the laminin receptor may be involved in hematogenous metastases formation.

Preincubation of metastatic murine melanoma cells with syngeneic whole laminin followed by tail vein injection increased tumor cell retention in the lung and strongly stimulated metastases formation. The domain of the laminin molecule responsible for stimulating metastases was identified. Laminin is a cross-shaped molecule with three short arms and one long arm. All arms have globular end regions. Purified protease-derived fragments of laminin were prepared which $(a)$ lacked only the long arm of the molecule (alpha fragment) or, (b) lacked both the long arm and the globular end regions of the short arms $\left(C_{1}\right.$ fragment). Both types of fragments contained the laminin receptor binding region. The fragments had opposite effects on metastases. The alpha fragment stimulated metastases formation to the same extent as whole laminin. In contrast, the $C_{1}$ fragment greatly reduced or abolished metastases formation in a dose-dependent manner. The $C_{1}$ fragment also inhibited tumor cell attachment to whole amnion basement membrane in vitro. We conclude that intact globular end regions on the short arms (but not the long arm) of the cell surface receptor-bound laminin molecule are necessary for stimulating metastases by the intravenous route.

\section{Introduction}

Metastasis is a complex multistep process in which cell surface components may play a role (1-7). Metastasizing tumor cells

Received for publication 9 April 1984 and in revised form 25 May 1984.

The Journal of Clinical Investigation, Inc.

Volume 74, September 1984, 843-848 traverse endothelial basement membranes during both entrance and egress from the circulation (8). The initial step of this traversal is thought to be attachment, which may be mediated in part through tumor cell surface receptor binding to laminin, a glycoprotein uniquely localized to basement membranes (1-4). We have previously demonstrated that human carcinoma cells and murine BL6 melanoma cells bind laminin with high affinity and that they possess a cell surface plasma membrane laminin receptor with a $M_{\mathrm{r}}$ of $\sim 67,000$ (1-3). A similar receptor has been identified on murine fibrosarcoma cells (4). Murine melanoma cells can be selected for metastatic propensity based on their ability to use laminin to attach to type IV collagen in vitro (9). Those tumor cells which preferentially utilized laminin for attachment exhibited a 10-fold increase in metastatic propensity (9). The laminin molecule has the structure of a "cross" by electron microscopy with one long arm $(75 \mathrm{~nm})$ and three short arms $(37 \mathrm{~nm})$, each containing globular end regions $(1,5,10)$. The carbohydrate composition of laminin is heterogeneous. Specific sugar moieties are enriched on the globular end regions compared with the rod-shaped portions of the molecule (10). Digestion of laminin with alpha thrombin will remove the long arm but leave the short arms intact (11). Cathepsin G or chymotrypsin will produce a laminin fragment devoid of the long arm and the globular end regions of the short arms (11). The $C_{1}$ fragment is " $T$ " shaped and contains the disulfide "knot" where the three short arms are joined together.

\section{Methods}

In the present study, we have investigated the effect of whole laminin and its two purified protease fragments on the production of pulmonary metastases by BL6 melanoma cells injected intravenously. BL6 melanoma cells are syngeneic in the C57 black mouse. The growth and attachment properties of this line have been described previously $(9,12)$. BL6 cells were grown in RPMI 1640 media supplemented with 10\% fetal bovine serum (Flow Laboratories, Inc., McLean, VA).

Syngeneic laminin was extracted from the C57 black mouse Engelbreth-Holm-Swarm tumor in $50 \mathrm{mM}$ Tris, $0.5 \mathrm{M} \mathrm{NaCl}$, pH 7.6, and purified by DEAE-cellulose and agarose A-5 M column chromatography as described previously (1). The alpha fragment and the $C_{1}$ fragment of laminin were purified and characterized by rotary shadowing electron microscopy as described previously $(1,2,11)$. The alpha fragment was produced by complete digestion of the $\beta$-subunit of 
laminin by thrombin, verified by SDS-polyacrylamide slab gel electrophoresis. High pressure liquid chromatography (HPLC) ${ }^{1}$ was used to separate the $\alpha$-subunit of laminin remaining after thrombin digestion from other low molecular weight components in the digestion mixture, such as enzymes or contaminants. Purification of the $\alpha$-subunit was verified by $3-12 \%$ gradient gel electrophoresis. The $C_{1}$ fragment was produced in an analogous manner with digestion of laminin with chymotrypsin. Complete digestion of the $\alpha$-subunit was achieved and verified by SDS-polyacrylamide gel electrophoresis. The fragment was purified by HPLC and verified by 3-12\% gradient gel electrophoresis.

BL6 cells were gently trypsinized and washed in serum-free RPMI media. The cells were incubated for $3 \mathrm{~h}$ at $37^{\circ} \mathrm{C}$ to allow for laminin receptor regeneration. Laminin receptor regeneration was verified as described previously (3). The suspended cells were then incubated in serum-free media with either whole laminin or the purified fragments. The incubation was carried out under gentle agitation for $30 \mathrm{~min}$ at room temperature. After incubation and cell washing, a single cell suspension (0.5-2.0 $\times 10^{5}$ cells) was injected via tail vein in 3-wk-old C57 black female mice. Viability of $>95 \%$ (by Trypan blue exclusion) and the absence of cell clumps was verified by hemacytometer inspection of the cells after incubation immediately before injection. As further control for the possible effects of laminin on homotypic cell clumping, BL6 cells were incubated with increasing concentrations of laminin ranging from $10 \mu \mathrm{g} / \mathrm{ml}$ to $1,000 \mu \mathrm{g} / \mathrm{ml}$, and the number and size of clumps were measured. As a control for laminin's effect on heterotypic cell clumping, BL6 cells were incubated with blood of C57 mice and increasing concentrations of laminin.

All mice were sacrificed 3 wk after injection. The lungs were removed, inflated with Bouin's fixative, and the number of metastases was determined by inspecting separated lung lobes with a dissecting microscope. As an additional control for viability, tumor cells having undergone preincubation with whole laminin or the laminin fragments were injected into the subcutaneous tissue and tumorigenicity was assessed.

BL6 tumor cells were harvested using EDTA or trypsin and suspended in $0.05 \mathrm{M}$ Tris/saline buffer, $\mathrm{pH} 7.4$, with calcium $(5 \mathrm{mM})$ and magnesium $(1 \mathrm{mM})$. BL6 tumor cells $\left(2 \times 10^{5}\right)$ were incubated for $60 \mathrm{~min}$ at $25^{\circ} \mathrm{C}$ in a volume of $1 \mathrm{ml}$ with ${ }^{125}$ I-labeled laminin with or without excess competitor (3).

Additional binding experiments were performed with ${ }^{125}$ I-labeled alpha fragment and ${ }^{125}$ I-labeled $C_{1}$ fragment. Scatchard analyses were performed.

Visual verification of laminin binding to BL6 tumor cells was demonstrated by first growing the cells for $24 \mathrm{~h}$ on cover slips. The monolayer was incubated in laminin $(10 \mu \mathrm{g} / \mathrm{ml})$ for $1 \mathrm{~h}$, washed, and air dried. Rabbit anti-laminin antibodies followed by fluoresceinconjugated goat anti-rabbit antibodies were used to identify bound laminin.

The tumor cells were labeled with $\left[{ }^{125} I\right] 5$-iodo-2'-deoxyuridine (IUdR) as described previously (13). The labeled cells were preincubated with the ligands as described in Table $I$. The number of mice in each group was 8 , with $25,000 \mathrm{cpm}\left(0.75 \times 10^{5}\right.$ cells $)$ injected per mouse. At various time intervals after injection, the mice were sacrificed and the total radioactivity in each lung was counted (14).

Intact native amnion membrane surfaces were prepared as described previously (15). The basement membrane surface was verified to contain both abundant laminin and type IV collagen by immunohis-

1. Abbreviations used in this paper: HPLC, high pressure liquid chromatography; IUdR, 5-iodo-2'-deoxyuridine. tology. Attachment was conducted in serum-free media at $37^{\circ} \mathrm{C}$ using amnion chambers containing a surface area of $1.5 \mathrm{~cm}^{2}$. Labeled tumor cells were placed in these chambers. The basement membrane surface was washed at a series of time intervals and the number of attached cells was determined by counting the bound radioactivity.

\section{Results}

Table I and Fig. 1 shows that cell surface-bound whole laminin stimulated metastases, whereas the $C_{1}$ fragment markedly inhibited metastases. For a constant amount of laminin or the $C_{1}$ fragment, the effect was greater when fewer cells were injected. This is in keeping with the existence of a limited number of receptors and less ligand available per cell as the cell number increases. Separate metastases assays were performed in which a constant amount of cells were treated with different concentrations of ligand. As shown in Table II, the alpha fragment stimulated metastases to the same extent as whole laminin. Thus, the long arm of the laminin molecule is not necessary for the effect. The $C_{1}$ fragment inhibited metastases formation in a dose-dependent manner. This indicates that intact globular end regions on the short arms of laminin are necessary for the stimulatory effect on metastases. The observed effects on metastases were not the result of altered tumorigenicity as $100 \%$ tumorigenicity was observed in all groups with no differences in subcutaneous growth rate.

Since cell clumping is associated with an increase in metastases (16), we wanted to exclude laminin's possible effect on cell clumping as the explanation for the stimulatory effect

Table I. Effect of Whole Laminin or Its $C_{l}$ Fragment on Pulmonary Metastases Formation

\begin{tabular}{llllll}
\hline & & \multicolumn{4}{l}{ Pulmonary metastases median (range) } \\
\cline { 5 - 6 } $\begin{array}{l}\text { Experi- } \\
\text { ment }\end{array}$ & $\begin{array}{l}\text { No. of cells } \\
\text { injected }\end{array}$ & No. & Control & $\begin{array}{l}\text { + Laminin } \\
10 \mu \mathrm{g} / \mathrm{ml}\end{array}$ & $\begin{array}{l}+\mathrm{C}_{1} \\
10 \mu \mathrm{g} / \mathrm{ml}\end{array}$ \\
\hline 1 & $0.5 \times 10^{5}$ & 10 & $12(3-22)$ & $72(38-90)$ & - \\
2 & $0.5 \times 10^{5}$ & 10 & $15(5-18)$ & $65(33-80)$ & - \\
3 & $0.75 \times 10^{5}$ & 10 & $28(15-30)$ & $110(45-130)$ & $1(0-6)$ \\
4 & $0.75 \times 10^{5}$ & 10 & $18(6-26)$ & $80(30-110)$ & $2(0-5)$ \\
5 & $1.0 \times 10^{5}$ & 10 & $75(25-90)$ & $165(80-240)$ & $5(0-10)$ \\
6 & $1.0 \times 10^{5}$ & 5 & $85(30-100)$ & $122(24-162)$ & $6(0-16)$ \\
7 & $2.0 \times 10^{5}$ & 10 & $98(50-106)$ & $210(150-290)$ & $40(28-55)$
\end{tabular}

Effect of whole laminin or its $C_{1}$ fragment on pulmonary metastases formation Murine BL6 melanoma cells were trypsinized and allowed to regenerate cell surface laminin receptors. The cells were preincubated for $30 \mathrm{~min}$ at $25^{\circ} \mathrm{C}$ in serum-free media containing whole laminin or the $C_{1}$ fragment at a concentration of $10 \mu \mathrm{g} / \mathrm{ml}$. Control cells were incubated in media alone. The washed cells were injected via tail vein. In all groups, at least $90 \%$ of the cells were in single cell form. The number of cells injected per mouse and the number of mice (No.) in each group is listed. At 3 wk after injection, all mice were sacrified and the number of pulmonary metastases were counted in separate lung lobes. Significant differences between the treatment groups and the control $(P<0.05)$ were noted for all experiments except no. $7\left(+C_{1}\right.$ group $)$ using both the Student's $t$ test and the Mann-Whitney test. 
A

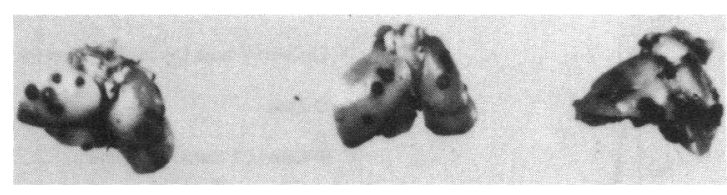

B

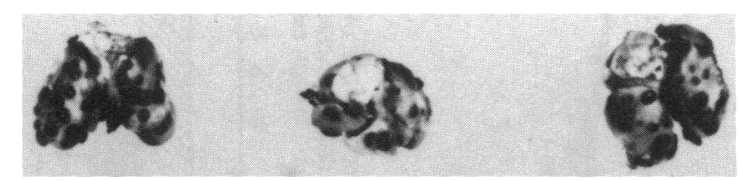

C

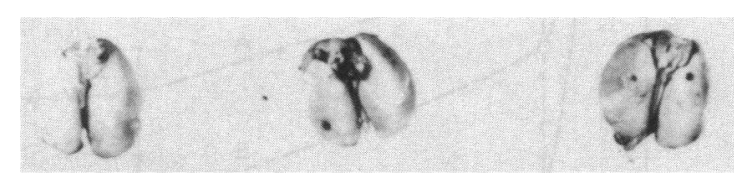

Figure 1. Representative lungs from experiment 4, Table I. (A) control group; $(B)$ laminin-treated group; $(C) \mathrm{C}_{1}$ fragment-treated group. The $C_{1}$ fragment markedly reduced the number of metastases (black colonies) compared with the other two groups. In all groups, $>95 \%$ of the metastases were found exclusively in the lungs.

on metastases. No appreciable effect of laminin on either homotypic or heterotypic cell clumping could be appreciated except at very high concentrations (Fig. 2). The stimulatory effect of laminin on metastases occurred at concentrations of $10 \mu \mathrm{g} / \mathrm{ml}$; appreciable clumping did not occur until concentrations of $1,000 \mu \mathrm{g} / \mathrm{ml}$ were used.

We investigated the properties of the laminin fragments further by comparing their ability to bind to the laminin receptor. Suspended BL6 cells exhibited saturable binding for laminin. Scatchard analysis demonstrated 90-115,000 binding sites/cell with high affinity $\left(K_{d}=2.2 \mathrm{nM}\right)$. The $C_{1}$ fragment and the alpha fragment competed for the laminin receptor as well as the whole laminin molecule and gave virtually identical Scatchard analyses (Fig. 3). Collagen, denatured laminin, and fibronectin did not compete for binding. The $K_{d}$ for the binding of the fragments was identical to that found with whole laminin. Therefore, these data indicate that the long arm and the globular end regions of the laminin molecule are not required for binding to the tumor cell surface laminin receptor. The receptor binding site resides somewhere on the rod-shaped portions of the short arms. Binding of laminin to the tumor cell surface was visually verified by immunofluorescence studies utilizing the addition of exogenous laminin to a monolayer of cultured BL6 cells followed by rabbit antilaminin and fluorescein-conjugated goat anti-rabbit antibodies (Fig. $4 A$ ). In the absence of exogenous laminin, surface immunofluorescence was absent (Fig. $4 \mathrm{~B}$ ).

To investigate the mechanism of the observed effect on pulmonary metastases, BL6 tumor cells were labeled with $\left[{ }^{125}\right.$ I]IUdR $(13,14)$ and treated with the ligand. The time
Table II. Dose-dependent Effect of Laminin Fragments on Pulmonary Metastases Formation

\begin{tabular}{|c|c|c|}
\hline Experimental group & $\begin{array}{l}\text { Pulmonary } \\
\text { metastases } \\
\text { median (range) }\end{array}$ & Percent change \\
\hline A. BL6 tumor cells alone & $19(10-30)$ & - \\
\hline \multicolumn{3}{|l|}{$\begin{array}{c}\text { B. BL6 tumor cells } \\
\text { + laminin }\end{array}$} \\
\hline $1 \mu \mathrm{g} / \mathrm{ml}$ & $34(22-68)$ & $100 \%$ increase \\
\hline $10 \mu \mathrm{g} / \mathrm{ml}$ & $80(39-120)$ & $300 \%$ increase \\
\hline $100 \mu \mathrm{g} / \mathrm{ml}$ & $102(55-141)$ & $400 \%$ increase \\
\hline \multicolumn{3}{|l|}{$\begin{array}{l}\text { C. BL6 tumor cells } \\
\qquad+ \text { alpha fragment }\end{array}$} \\
\hline $10 \mu \mathrm{g} / \mathrm{ml}$ & $72(58-130)$ & $280 \%$ increase \\
\hline $100 \mu \mathrm{g} / \mathrm{ml}$ & $114(42-138)$ & $400 \%$ increase \\
\hline \multicolumn{3}{|l|}{$\begin{array}{l}\text { D. BL6 tumor cells } \\
+\mathrm{C}_{1} \text { fragment }\end{array}$} \\
\hline $1 \mu \mathrm{g} / \mathrm{ml}$ & $18(12-29)$ & No change \\
\hline $10 \mu \mathrm{g} / \mathrm{ml}$ & $8(6-9)$ & $50 \%$ decrease \\
\hline $100 \mu \mathrm{g} / \mathrm{ml}$ & $2(0-10)$ & $90 \%$ decrease \\
\hline
\end{tabular}

Dose-dependent effect of laminin fragments on pulmonary metastases formation. The experiments were conducted as described in the legend to Table I, except that the tumor cells were incubated with a series of different concentrations of the ligand. The structure of the laminin molecule or the fragment is depicted. The number of cells injected was $0.5 \times 10^{5}$ with 10 mice in each experimental group. Aliquots of the same cell suspension were injected subcutaneously.

$100 \%$ tumorigenicity was observed in all groups with no differences in subcutaneous tumor growth rate.

course of their lung retention was followed after intravenous injection. The majority of treated or untreated cells immediately arrested in the lung. Thereafter, the rate of clearance was significantly different for the treated groups compared with the control (Fig. 4). The $C_{1}$ fragment decreased lung retention in a manner which became more pronounced at increasing time. At $20 \mathrm{~h}$, there was greater than a fivefold decrease in the percent of cells retained. In contrast, treatment of cells with whole laminin increased lung retention at all times after $30 \mathrm{~min}$.

The lung retention data suggested that tumor cell attachment (or rate of detachment) from the pulmonary vascular basement membrane may play a role in the observed effect. Therefore, [ $\left.{ }^{125} \mathrm{I}\right] \mathrm{IUdR}$-labeled BL6 tumor cells were studied for their attachment properties on whole amnion basement membrane surfaces. The attachment of tumor cells in vitro to native basement membrane of human amnion was significantly altered by the addition of exogenous laminin or the $C_{1}$ laminin fragment. The time course of attachment reached a plateau in all three groups at $3 \mathrm{~h}$. Whole laminin stimulated attachment. 


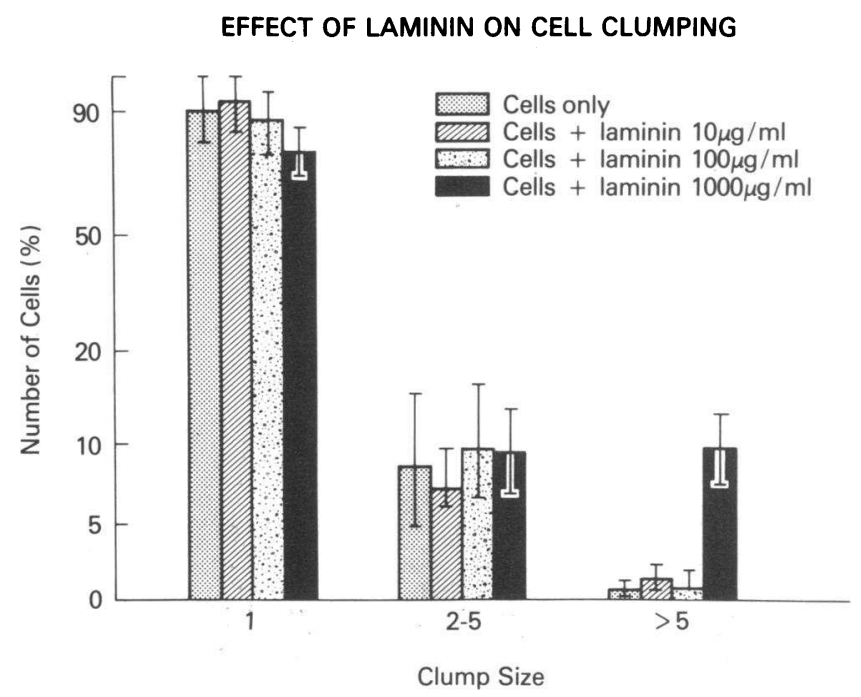

Figure 2. Clumping of cells by laminin. The cells were incubated with increasing concentrations of laminin and the cells were counted on a hemacytometer. The histogram depicts number of cells in single form, in clumps of 2-5 cells, and $>5$ cells. Laminin had no effect on cell clumping except at very high $(1,000 \mu \mathrm{g} / \mathrm{ml})$ concentrations.

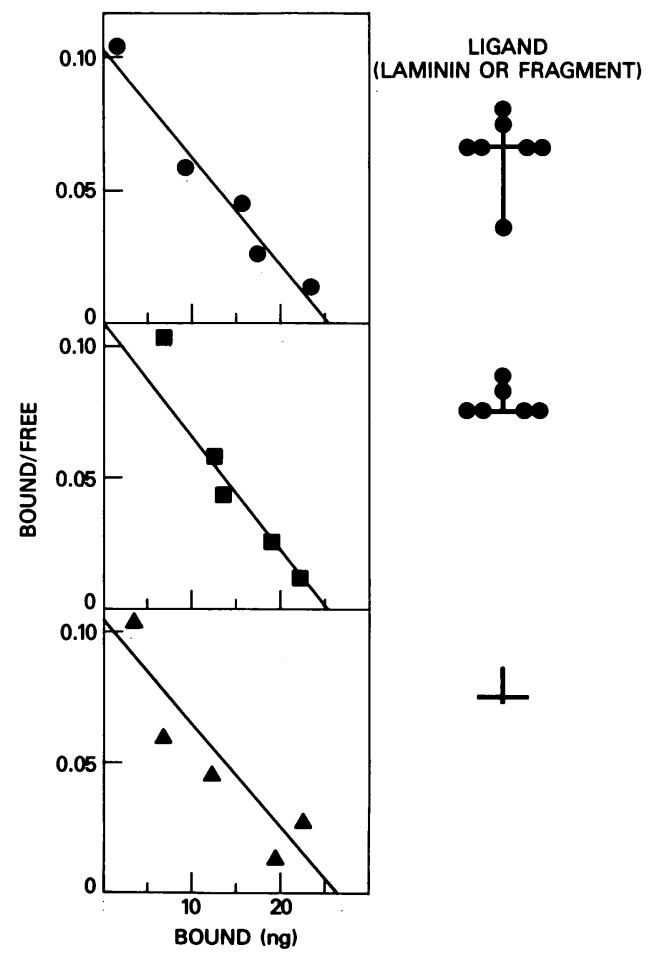

Figure 3. Scatchard analyses comparison for specific binding of laminin or laminin fragments to BL6 melanoma cells. The structure of the molecule is depicted to the right of its respective Scatchard plot. The Scatchard plots were linear and with a similar $K_{d}$ of $\sim 2 \mathrm{nM}$. The bound fraction is expressed per $2 \times 10^{6}$ cells.

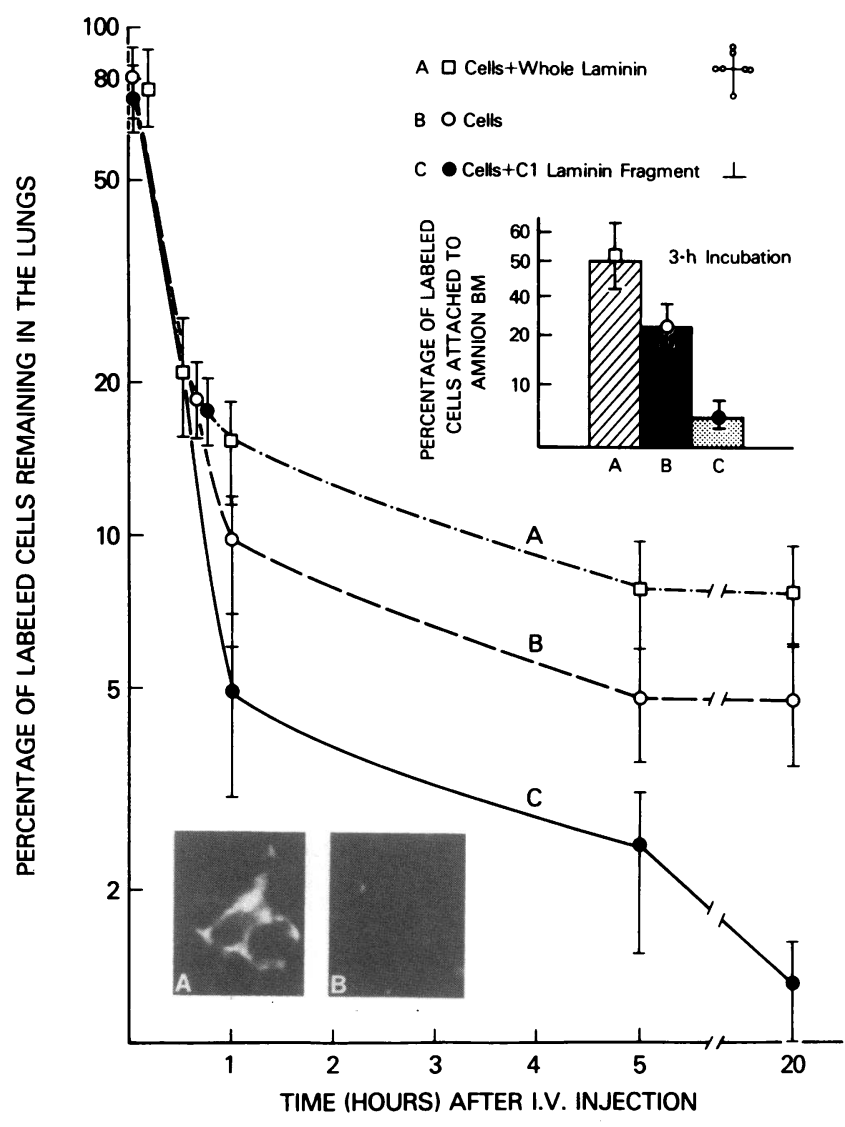

Figure 4. Pulmonary retention of labeled BL6 tumor cells injected intravenously. Whole laminin increased pulmonary retention whereas the $C_{1}$ fragment produced a significant decrease in retention which became more pronounced at later times. Visualization of laminin binding to BL6 tumor cells: $(A)$ tumor cells with exogenous laminin added, $(B)$ tumor cells without exogenous laminin. Insert: Amnion basement membrane attachment in vitro. [ $\left.I^{125}\right] I U d R$-labeled tumor cells attached were measured. The plateau of attachment was reached at $3 \mathrm{~h}$. The data shown is the percent attached cells: $(A)$ cells treated with whole laminin $(10 \mu \mathrm{g} / \mathrm{ml}),(B)$ untreated cells, $(C)$ cells treated with the $C_{1}$ fragment $(10 \mu \mathrm{g} / \mathrm{ml})$.

In contrast, the $C_{1}$ fragment reduced attachment (Fig. 4 , insert).

\section{Discussion}

One purpose of this study was to demonstrate a role for the laminin receptor in hematogenous metastases formation. A second purpose was to identify the domains on the laminin molecule responsible for such receptor-basement membrane interaction.

Injection of BL6 cells preincubated with laminin resulted in both their increased retention in the lungs as well as enhanced metastases formation. In contrast to these findings, 
BL6 cells preincubated with the $C_{1}$ fragment resulted in both decreased lung retention and decreased metastases. From this data several conclusions are likely. The first is that the mechanism by which laminin and its $C_{1}$ fragment alter pulmonary metastases involves the retention of tumor cells in the lungs. With the addition of laminin, more cells are retained (Fig. 4), and therefore, more metastases are produced (Fig. 1). With the addition of the $C_{1}$ fragment, fewer cells are retained (Fig. 4) and fewer metastases occur (Fig. 1). The differences in metastases noted in the laminin- vs. $\mathrm{C}_{1}$-treated groups are not the result of differential effects of these ligands on tumor cell growth since no differences in subcutaneous tumor growth were appreciated. Therefore, further insight into the mechanism of the effect of laminin and its $C_{1}$ fragment on metastasis rested on understanding the mechanism by which these ligands altered pulmonary retention.

One possible mechanism which could explain the effects on lung retention and metastases formation is an immunologic one mediated specifically through $\mathrm{T}$ lymphocytes or nonspecifically through natural killer (NK) cells or macrophages. Both immunologic mechanisms were considered unlikely. The source of laminin was the Engelbreth-Holm-Swarm sarcoma, a tumor syngeneic in the C57 mouse. The BL6 tumor is syngeneic also in the C57 mouse and the tail vein injection studies were performed in this same murine model. Therefore, since no "foreign" antigens were injected, a cellular or humoral immunologic response would be unlikely. However, intravascular injection of tumor cells with syngeneic laminin could still elicit a natural killer cell or macrophage-mediated response. Yet, it is unlikely that such a response could explain the opposite effects on metastasis produced by whole laminin and its $C_{1}$ fragment. Any macrophage response elicited by the $C_{1}$ fragment should also be seen with the parent molecule, whole laminin.

Another possible mechanism which could explain the effects on lung retention and metastases formation, especially those produced by the $C_{1}$ fragment, is the presence of endotoxin or some other contaminant in our preparation. The $C_{1}$ fragment had been purified by HPLC and all possible low molecular weight compounds, such as endotoxin, removed. Furthermore, the $C_{1}$ fragment did not decrease subcutaneous tumorigenicity.

Another possible mechanism which could explain the effects on lung retention and metastases, especially those produced by whole laminin, is cell clumping. Since size and number of cell clumps injected can alone increase metastases (16), we specifically tested the effect of increasing concentrations of laminin on cell clumping (Fig. 2). There was no increase in number or size of cell clumps in the laminin-treated group compared with controls. Furthermore, cells were not injected into the mice unless at least $90 \%$ of the cells were in single cell form for all the experimental groups. No significant effects were noted on either homotypic or heterotypic clumping at the concentrations used for the metastases experiments. Laminin did agglutinate cells when used at concentrations of 100 times that used for the in vivo experiments. The "sticky" nature of this glycoprotein makes it not surprising that laminin would agglutinate at high concentrations.

The mechanism most likely to explain our findings is one which involves interaction of tumor cells with vascular basement membrane. There is no known native capillary endothelial basement membrane model to study tumor cell attachment, so we chose the human amnion as our model to study attachment. The human amnion has proved a reliable model for studying cell attachment and invasion (15). Our in vitro data with this model indicate that laminin promotes attachment of BL6 tumor cells to native basement membrane whereas the $C_{1}$ fragment inhibits attachment (Fig. 4, insert). Therefore, one hypothesis which explains the data is that laminin promotes and the $C_{1}$ fragment inhibits interaction of BL6 cells with vascular basement membrane in the lung. This would explain the opposite effects of these ligands on pulmonary retention.

In this hypothesis, we have deemphasized the potential importance of the endothelial cell. Whatever the role of this cell in metastasis, the tumor cell must still interact with the basement membrane of the capillary vessel in order to escape from the circulation. There is evidence in the literature to suggest that the endothelial cell may retract and expose its basement membrane to nearby circulating tumor cells $(17,18)$.

Tumor cells with free laminin receptors then may utilize these receptors to interact with the laminin in vascular basement membrane. Saturating these receptors with added laminin results in an increase rather than a decrease in lung retention and metastasis because BL6 tumor cells with added laminin utilize the globular end regions of this molecule to interact with the endothelium or the basement membrane type IV collagen or proteoglycan. In a similar manner, other tumor cells containing self-secreted laminin already on their surface may utilize this molecule to promote their attachment to basement membranes. This argument has been supported by the study of Varani et al. (19) demonstrating an endogenous laminin-like substance on the cell surface of highly metastatic fibrosarcoma cells. This substance was absent from low metastatic cells derived from the same parent. The addition of laminin to these low metastatic cells promoted metastasis.

However, the $C_{1}$ laminin fragment, a fragment of laminin which lacks the globular end regions but binds to the cell, can inhibit metastases because it can block the laminin receptor without increasing the cell's ability to interact with other basement membrane components.

\section{References}

1. Rao, C. N., I. M. Margulies, T. S. Tralka, V. P. Terranova, J. A. Madri, and L. A. Liotta. 1982. Isolation of a subunit of laminin and its role in molecular structure and tumor cell attachment. J. Biol. Chem. 257:9740-9744.

2. Terranova, V. P., C. N. Rao, T. Kalebic, I. M. Margulies, and L. A. Liotta. 1983. Laminin receptor on human breast carcinoma cells. Proc. Natl. Acad. Sci. USA. 80:444-448. 
3. Rao, N. C., S. H. Barsky, V. P. Terranova, and L. A. Liotta. 1983. Isolation of a tumor cell laminin receptor. Biochem. Biophys. Res. Commun. 111:804-808.

4. Malinoff, H. L., and M. S. Wicha. 1983. Isolation of a cell surface receptor protein for laminin from murine fibrosarcoma cells. J. Cell. Biol. 96:1475-1479.

5. Engel, J., E. Odermott, A. Engel, J. A. Madri, H. Furthmayr, H. Rohde, and R. Timpl. 1981. Shapes, domain, organization, and flexibility of laminin and fibronectin, two multifunctional proteins of the extracellular matrix. J. Mol. Biol. 150:97-120.

6. Nicolson, G. L., and G. Poste. 1976. The cancer cell: dynamic aspects and modifications in cell-surface organization. N. Engl. J. Med. 295:197-203, 253-258.

7. Poste, G., and G. L. Nicolson. 1983. Biomembranes. Plenum Publishing Corp., New York. 341-364.

8. Liotta, L. A., and I. R. Hart. 1982. Tumor Invasion and Metastases. Martinus Nijhoff, The Hague. 534 pp.

9. Terranova, V. P., L. A. Liotta, R. G. Russo, and G. P. Martin 1982. Role of laminin in the attachment and metastasis of murine tumor cells. Cancer Res. 42:2265-2269.

10. Rao, C. N., I. J. Goldstein, and L. A. Liotta. 1983. Lectin binding domains on laminin. Arch. Biochem. Biophys. 227:118-124.

11. Rao, C. N., I. M. K. Margulies, R. H. Goldfarb, J. A. Madri, D. T. Woodley, and L. A. Liotta. 1982. Differential proteolytic susceptibility of laminin alpha and beta subunits. Arch. Biochem. Biophys. 219:65-70.

12. Hart, I. R., and I. J. Fidler. 1980. The role of organ selectivity in the determination of metastatic patterns of the B16 melanoma. Cancer Res. 40:2281-2287.

13. Fidler, I. J. 1970. Metastasis: quantitative analysis of distribution and fate of tumor emboli labelled with ${ }^{125}$ I-5-iodo-2'-deoxyuridine. $J$. Natl. Cancer Inst. 45:773-782.

14. Liotta, L. A., and C. Delisi. 1977. Method for quantitating tumor cell removal and tumor cell invasive capacity in experimental metastases. Cancer Res. 37:4003-4008.

15. Russo, R. G., C. M. Foltz, and L. A. Liotta. 1983. New invasion assay using endothelial cells grown on native human basement membrane. Clin. Exp. Metastasis. 1:115-127.

16. Liotta, L. A., J. Kleinerman, and G. M. Saidel. 1976. The significance of hematogenous tumor cell clumps in the metastatic process. Cancer Res. 36:889-894.

17. Crissman, J., B. Sloane, and R. Ryan. 1984. Correlation of cathepsin B and metastatic potential in malignant neoplasia. Lab. Invest. 50:13A. (Abstr.)

18. Nicolson, G. L., T. Irimura, M. Nakajima, and J. Estrada. 1984. Metastatic cell attachment to and invasion of vascular endothelium and its underlying basal lamina using endothelial cell monolayers. In Cancer Invasion and Metastasis: Biologic and Therapeutic Aspects. G. L. Nicolson and L. Milas, editors. Raven Press, New York. 145168.

19. Varani, J., E. J. Lovett, J. P. McCoy, S. Shibata, D. E. Maddox, I. J. Goldstein, and M. Wicha. 1983. Differential expression of a lamininlike substance by high and low metastatic tumor cells. Am. J. Pathol. 111:27-34. 